\title{
Nonlinear Steady-State Model Based Gas Turbine Health Status Estimation Approach with Improved Particle Swarm Optimization Algorithm
}

\author{
Yulong Ying, ${ }^{1}$ Yunpeng Cao, ${ }^{1}$ Shuying Li, ${ }^{1}$ and Jingchao $\mathrm{Li}^{2}$ \\ ${ }^{1}$ College of Power and Energy Engineering, Harbin Engineering University, Harbin, China \\ ${ }^{2}$ Electronic Information College, Shanghai Dianji University, Shanghai 200240, China \\ Correspondence should be addressed to Yulong Ying; yingyulong060313@163.com
}

Received 28 December 2014; Revised 25 May 2015; Accepted 3 June 2015

Academic Editor: Alessandro Gasparetto

Copyright (C) 2015 Yulong Ying et al. This is an open access article distributed under the Creative Commons Attribution License, which permits unrestricted use, distribution, and reproduction in any medium, provided the original work is properly cited.

In the lifespan of a gas turbine engine, abrupt faults and performance degradation of its gas-path components may happen; however the performance degradation is not easily foreseeable when the level of degradation is small. Gas path analysis (GPA) method has been widely applied to monitor gas turbine engine health status as it can easily obtain the magnitudes of the detected component faults. However, when the number of components within engine is large or/and the measurement noise level is high, the smearing effect may be strong and the degraded components may not be recognized. In order to improve diagnostic effect, a nonlinear steady-state model based gas turbine health status estimation approach with improved particle swarm optimization algorithm (PSO-GPA) has been proposed in this study. The proposed approach has been tested in ten test cases where the degradation of a model three-shaft marine engine has been analyzed. These case studies have shown that the approach can accurately search and isolate the degraded components and further quantify the degradation for major gas-path components. Compared with the typical GPA method, the approach has shown better measurement noise immunity and diagnostic accuracy.

\section{Introduction}

Gas turbine engines have been applied in a widespread manner in power plants, aviation industry, and navigation industry. In the lifespan of a gas turbine engine, various abrupt faults and performance degradation of its gas-path components may happen. And however the performance degradation is not easily foreseeable when the level of degradation is small [1]. Thus the current engine performance and health status are considerably important and useful information for engine users to detect performance degradation.

Many gas-path analysis approaches have been proposed to estimate the performance and health status for gas turbine. From the linear GPA method developed by Urban in the late 1960s [2], a series of GPA methods were proposed, such as thermodynamic model based GPA methods (e.g., adaptive linear and nonlinear GPA methods [3-5] and genetic algorithm based GPA method [6-9]) and artificial intelligence based GPA methods (e.g., artificial neural networks [10, 11], rule based expert system [12-14], and rule based fuzzy expert system [15]).

The common merit of artificial intelligence (AI) based GPA methods is no need of a complex engine thermodynamic performance model, and only the relation information between fault symptom and performance degradation is required. However, the accumulation of knowledge by experiments and experience is a costly and uneasy job and most case studies show that AI based GPA methods may effectively isolate the faulty components but not easily obtain the magnitudes of the detected faults.

The reason why model based GPA method has been widely applied to monitor gas turbine engine health status is that model based GPA can easily obtain the magnitudes of the detected component faults through the usage of a thermodynamic performance model which relates gas-path measurable parameters (e.g., temperatures, pressures, and shaft rotational speeds) to the fundamental component performance parameters (e.g., pressure ratio, mass flow rate, 
and isentropic efficiency) [16]. However, when the number of components involved in fault diagnosis is large or/and the measurement noise level is high, the smearing effect may be so strong and the degraded components may not be identified.

In this paper, a nonlinear steady-state model based gas turbine health status estimation approach with improved particle swarm optimization algorithm (PSO-GPA) has been developed to detect performance degradation of engine components by the usage of gas-path measurements with the existence of measurement noise. The developed approach has been tested in ten Test Cases where the degradation of a model three-shaft marine engine has been analyzed. Analysis and conclusions were made accordingly compared with the typical GPA method.

\section{Methodology}

Normally, gas turbine engine overall health status is represented by gas-path component health parameters (i.e., compressor and turbine flow capacity indices and efficiency indices and combustor efficiency index), which represent a shift of the characteristic curves on component maps due to degradation [3]. However, this essential performance and health status information cannot be directly measured and thus cannot be easily monitored and diagnosed.

In the gas turbine operation, when some physical degraded problems of gas-path components happen, the component performance parameters (e.g., pressure ratio, mass flow rate, and isentropic efficiency) are changing and cause the deviation of gas-path measurable parameters, such as temperatures, pressures, and shaft rotational speeds [2]. Thus the deviation of component performance parameters can be indicated by the deviation of gas-path measurement parameters and such deviation of component performance parameters may be due to varying operating conditions or engine performance degradation [5]. The thermodynamic relationship between engine gas-path measurement parameters and engine component performance parameters can be expressed with

$$
\vec{z}=f(\vec{p}, \vec{u})+\vec{v}
$$

where $\vec{z}$ is gas-path measurement parameter vector; $\vec{p}$ is engine component performance parameter vector; $\vec{u}$ is ambient and operating condition vector; $\vec{v}$ is transducer measurement noise vector.

Therefore, gas turbine health status estimation is a mathematical problem to obtain the deviation of engine component performance parameters $\Delta \vec{p}$ by the deviation of gaspath measurement parameters $\Delta \vec{z}$ after measurement noise reduction and data preprocessing against deviated ambient and operating conditions and further to obtain the gas-path component health parameters $\Delta \overrightarrow{S F}$ for assessment of engine overall health status.

When an engine is healthy and operates at a specified operating condition, the performance status of the engine is denoted by subscript " 0 ." When the engine operates at

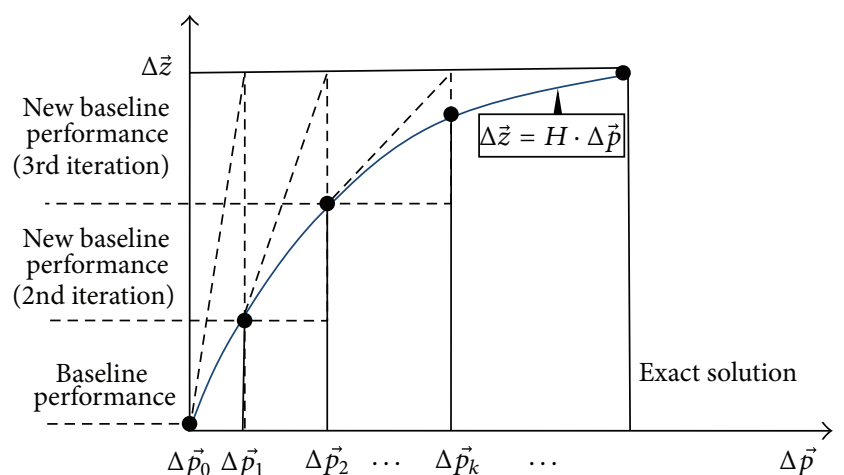

FIgURE 1: Simplified illustration of a typical GPA.

slightly deviated conditions due to varying operating conditions or/and engine performance degradation, the engine performance expressed with (1) can be expanded in a Taylor series expansion around condition " 0 " assuming that the engine performance deviation is small:

$$
\begin{aligned}
\vec{z}= & \overrightarrow{z_{0}}+\left.\frac{\delta f(\vec{p}, \vec{u})}{\delta \vec{p}}\right|_{0}\left(\vec{p}-\overrightarrow{p_{0}}\right)+\left.\frac{\delta f(\vec{p}, \vec{u})}{\delta \vec{u}}\right|_{0}\left(\vec{u}-\overrightarrow{u_{0}}\right) \\
& + \text { HOT }
\end{aligned}
$$

where HOT is higher order terms of the expansion and can be neglected when the performance deviation is small. Thus, the following equation can be obtained:

$$
\Delta \vec{z}=H \cdot \Delta \vec{p}+H^{\prime} \cdot \Delta \vec{u},
$$

where $H$ is the influence coefficient matrix (ICM) and $H^{-1}$ is the fault coefficient matrix (FCM). The deviation of component performance parameters can be predicted by inverting $H$ to $H^{-1}$ after measurement data preprocessing against deviated ambient and operating conditions $\Delta \vec{u}$, leading to

$$
\Delta \vec{p}=H^{-1} \cdot \Delta \vec{z}
$$

Due to the nonlinearity of engine performance, an iterative process (a Newton-Raphson method) is used to obtain the deviation of engine component performance parameters $\Delta \vec{p}$ until a converged solution is obtained where the predicted gas-path measurement parameters are very close to the actual measurement parameters, as shown in Figure 1.

And then the deviation of gas-path component health parameters $\Delta \overrightarrow{S F}$ can be obtained by comparing healthy and degraded performance at component level.

\section{Proposed Algorithm}

3.1. Engine Health Parameters. When the level of degradation is small, it is always assumed that the characteristic maps of degraded components (i.e., compressors, combustors, and turbines) will keep more or less the same shape as their original maps based on the fact that the geometries of gas-path components do not change significantly after degradation. 
And then the degradation of gas-path components can be represented by the shift of the characteristic curves on the maps and such shift can be expressed by the component health parameters $\Delta \overrightarrow{S F}$, such as compressor and turbine flow capacity indices and efficiency indices and combustor efficiency index [9].

For the previous GPA methods (e.g., approaches developed by authors [3-5]), component health parameters for gas-path components were defined using component absolute performance parameters (e.g., mass flow rate $G$ and rotational speed $n$ for compressor and turbine). When the gas-path measurements are obtained at slightly different ambient conditions from baseline, they should be corrected to the baseline condition to eliminate the deviation of component performance parameters caused by varying ambient condition (e.g., ambient temperature, pressure, and humidity) due to the fact that component maps will change with ambient conditions. Here, to eliminate the inconvenience stated above, the component health parameters for gaspath components can be redefined using component similar performance parameters (e.g., corrected mass flow rate $G \sqrt{T^{*} \cdot R_{g}} / P^{*}$ and corrected rotational speed $n / \sqrt{T^{*} \cdot R_{g}}$ for compressor and turbine) due to the fact that component maps will not change with ambient conditions, where the same treatment can be found in the treatment of characteristic maps for compressor and turbine.

\subsubsection{Compressor Health Parameters. Consider}

$$
\begin{aligned}
S F_{\mathrm{C}, \mathrm{FC}} & =\frac{G_{\mathrm{C}, \mathrm{cor}, \mathrm{deg}}}{G_{\mathrm{C}, \mathrm{cor}}}, \\
\Delta S F_{\mathrm{C}, \mathrm{FC}} & =\frac{\left(G_{\mathrm{C}, \mathrm{cor}, \mathrm{deg}}-G_{\mathrm{C}, \mathrm{cor}}\right)}{G_{\mathrm{C}, \mathrm{cor}}}, \\
S F_{\mathrm{C}, \mathrm{Eff}} & =\frac{\eta_{\mathrm{C}, \mathrm{deg}}}{\eta_{\mathrm{C}}}, \\
\Delta S F_{\mathrm{C}, \mathrm{Eff}} & =\frac{\left(\eta_{\mathrm{C}, \mathrm{deg}}-\eta_{\mathrm{C}}\right)}{\eta_{\mathrm{C}}},
\end{aligned}
$$

where $S F_{\mathrm{C}, \mathrm{FC}}$ is compressor flow capacity index; $G_{\mathrm{C} \text {, cor,deg }}$ is compressor corrected flow capacity when the compressor is degraded; $G_{\mathrm{C} \text {,cor }}$ is compressor corrected flow capacity when the compressor is healthy; $S F_{\mathrm{C}, \mathrm{Eff}}$ is compressor isentropic efficiency index; $\eta_{C \text {,deg }}$ is compressor isentropic efficiency when the compressor is degraded; $\eta_{C}$ is compressor isentropic efficiency when the compressor is healthy.

3.1.2. Combustor Health Parameter. Combustor degradation can be represented with the degradation of combustor combustion efficiency:

$$
\begin{aligned}
S F_{\mathrm{B}, \mathrm{Eff}} & =\frac{\eta_{\mathrm{B}, \mathrm{deg}}}{\eta_{\mathrm{B}}}, \\
\Delta S F_{\mathrm{B}, \mathrm{Eff}} & =\frac{\left(\eta_{\mathrm{B}, \mathrm{deg}}-\eta_{\mathrm{B}}\right)}{\eta_{\mathrm{B}}},
\end{aligned}
$$

where $S F_{\mathrm{B}, \mathrm{Eff}}$ is combustor efficiency index; $\eta_{\mathrm{B} \text {,deg }}$ is combustion efficiency when the combustor is degraded; $\eta_{\mathrm{B}}$ is combustion efficiency when the combustor is healthy.

\subsubsection{Turbine Health Parameters. Consider}

$$
\begin{aligned}
S F_{\mathrm{T}, \mathrm{FC}} & =\frac{G_{\mathrm{T}, \mathrm{cor}, \mathrm{deg}}}{G_{\mathrm{T}, \mathrm{cor}}}, \\
\Delta S F_{\mathrm{T}, \mathrm{FC}} & =\frac{\left(G_{\mathrm{T}, \mathrm{cor}, \mathrm{deg}}-G_{\mathrm{T}, \mathrm{cor}}\right)}{G_{\mathrm{T}, \mathrm{cor}}}, \\
S F_{\mathrm{T}, \mathrm{Eff}} & =\frac{\eta_{\mathrm{T}, \mathrm{deg}}}{\eta_{\mathrm{T}}}, \\
\Delta S F_{\mathrm{T}, \mathrm{Eff}} & =\frac{\left(\eta_{\mathrm{T}, \mathrm{deg}}-\eta_{\mathrm{T}}\right)}{\eta_{\mathrm{T}}},
\end{aligned}
$$

where $S F_{\mathrm{T}, \mathrm{FC}}$ is turbine flow capacity index; $G_{\mathrm{T} \text {,cor,deg }}$ is turbine corrected flow capacity when the turbine is degraded; $G_{\mathrm{T} \text {,cor }}$ is turbine corrected flow capacity when the turbine is healthy; $S F_{\mathrm{T}, \mathrm{Eff}}$ is turbine isentropic efficiency index; $\eta_{\mathrm{T} \text {,deg }}$ is turbine isentropic efficiency when the compressor is degraded; $\eta_{\mathrm{T}}$ is turbine isentropic efficiency when the compressor is healthy.

3.2. Engine Performance Model. In order to isolate, detect, and quantify the component faults by PSO-GPA, a thermodynamic performance model which relates gas-path measurable parameters to component performance parameters for the target engine should be established.

3.2.1. Compressor Thermodynamic Model. Performance characteristics of compressors are usually described by compressor maps with nondimensional groups of corrected parameters and a general relation between these corrected parameters can be presented as follows:

$$
\begin{aligned}
G_{\mathrm{C}, \mathrm{cor}} & =f\left(n_{\mathrm{C}, \mathrm{cor}}, \pi_{\mathrm{C}}\right), \\
\eta_{\mathrm{C}} & =f\left(n_{\mathrm{C}, \mathrm{cor}}, \pi_{\mathrm{C}}\right),
\end{aligned}
$$

where $n_{\mathrm{C}, \mathrm{cor}}=n / \sqrt{T_{\text {in }}^{*} \cdot R_{g}}$ is compressor corrected rotational speed; $\pi_{\mathrm{C}}$ is compressor pressure ratio; $\eta_{\mathrm{C}}$ is compressor isentropic efficiency; $G_{\mathrm{C} \text {, cor }}=G_{\mathrm{C}} \sqrt{T_{\text {in }}^{*} \cdot R_{g}} / P_{\text {in }}^{*}$ is compressor corrected mass flow; $R_{g}$ is the specific gas constant; $T_{\text {in }}^{*}$ is the compressor air inlet temperature; $n$ is shaft rotational speed. $P_{\text {in }}^{*}$ is the compressor air inlet pressure; $G_{\mathrm{C}}$ is the compressor air mass flow.

When some physical degraded problems of compressors happen, the compressor performance parameters are changing which can be represented by the shift of the characteristic curves on the compressor characteristic maps and such shift can be expressed by the compressor health parameters as described in (6) and (8). 
Therefore the performance characteristics of actual compressor can be presented as follows:

$$
\begin{aligned}
G_{\mathrm{C}, \text { cor,deg }} & =f\left(n_{\mathrm{C}, \mathrm{cor}}, \pi_{\mathrm{C}}, \Delta S F_{\mathrm{C}, \mathrm{FC}}\right), \\
\eta_{\mathrm{C}, \mathrm{deg}} & =f\left(n_{\mathrm{C}, \mathrm{cor}}, \pi_{\mathrm{C}}, \Delta S F_{\mathrm{C}, \mathrm{Eff}}\right) .
\end{aligned}
$$

3.2.2. Combustor Thermodynamic Model. Compared with compressor and turbine, the performance characteristics of combustor are relatively simple and usually described by only pressure recovery coefficient and combustion efficiency. At large part-load operating range, combustor keeps high combustion efficiency for a clean or healthy combustion chamber. Introducing the combustor health parameter as described in (10), the performance characteristic of actual combustor can be expressed as follows:

$$
\eta_{\mathrm{B}, \mathrm{deg}}=f\left(\text { load, } \Delta S F_{\mathrm{B}, \mathrm{Eff}}\right) \text {, }
$$

where load is engine load power.

3.2.3. Turbine Thermodynamic Model. Like compressor, performance characteristics of turbines are usually described by turbine maps with nondimensional groups of corrected parameters and a general relation between these corrected parameters is the same as compressor.

When some physical degraded problems of turbines happen, the turbine performance parameters are changing which can be represented by the shift of the characteristic curves on the turbine characteristic maps and such shift can be expressed by the turbine health parameters as described in (12) and (14).

Therefore the performance characteristics of actual turbine can be presented as follows:

$$
\begin{aligned}
G_{\mathrm{T}, \text { cor }, \text { deg }} & =f\left(n_{\mathrm{T}, \text { cor }}, \pi_{\mathrm{T}}, \Delta S F_{\mathrm{T}, \mathrm{FC}}\right), \\
\eta_{\mathrm{T}, \mathrm{deg}} & =f\left(n_{\mathrm{T}, \mathrm{cor}}, \pi_{\mathrm{T}}, \Delta S F_{\mathrm{T}, \mathrm{Eff}}\right) .
\end{aligned}
$$

After the thermodynamic performance model of the target engine has been established, the on-design and offdesign steady-state performance of the target engine together with detailed measureable parameters at each gas-path station can be calculated. More detailed information about gas turbine performance modeling is described in [17-19]. And as component health parameters have been considered in the engine model, it can also easily be used for simulating faulty engine performance.

3.3. Particle Swarm Optimization Algorithm. Particle swarm optimization (PSO) is a biologically inspired technique derived from the collective behavior of bird flocks, developed by Eberhart and Kennedy [20] and first published in 1995 with an exponential increase in the number of publications since then. The detailed description of PSO can be referred to [21]. PSO is made up of a swarm of particles called population, and each particle represents a candidate solution. Elements of a particle represent parameters to be optimized. Particles fly through the solution space with a specified velocity for searching the optimal solution. Each particle has a memory helping it in keeping the track of its previous best position. The position of each particle is distinguished as personal best pBest and global best gBest; the velocity of each particle is adjusted according to its historical behavior and its neighbors, during flying through the solution space. Each move of particles is deeply influenced by its memory of previous useful parameters, its current position, and the group knowledge of the swarm. Thus, the particles have a tendency to fly towards improved search areas in the course of the searching process. The flow chart of PSO searching process is shown in Figure 2.

In searching process, the position and velocity of each particle are updated by tracking two extreme values, that is, personal best pBest and global best gBest, according to the following equation:

$$
\begin{aligned}
V_{i}^{k+1}= & W \cdot V_{i}^{k}+c 1 \cdot r 1 \cdot\left(\text { B Best }_{i}^{k}-\text { Present }_{i}^{k}\right) \\
& +c 2 \cdot r 2 \cdot\left(g B e s t^{k}-\text { Present }_{i}^{k}\right), \\
\text { Present }_{i}^{k+1}= & \text { Present }_{i}^{k}+V_{i}^{k+1},
\end{aligned}
$$

where $c 1$ and $c 2$ are acceleration constants and are usually set as $c 1=c 2=1.2 ; r 1$ and $r 2$ are random values in the range of 0 and $1 ; W$ is inertia weight and its value is set in the range of 0.1 and 0.9. $V_{i}^{k+1}$ is the velocity of the $i_{\text {th }}$ particle in the $(k+$ $1)_{\text {th }}$ generation; Present ${ }_{i}^{k}$ shows the position of each particle; pBest ${ }_{i}^{k}$ is the previous best position of each particle named particle best position, and $g B e s t^{k}$ is the best position of all the particles.

By continually updating positions, particles fly towards the position of the optimal solution in the solution space and then the searching process is finished with the final output global best solution gBest obtained.

Compared with genetic algorithm (GA) [22], PSO algorithm has no crossover and mutation operation, so its algorithm structure is simpler and the computational speed is faster. However, the phenomenon of back and forth searching near the global optimal solution easily appears in the traditional PSO algorithm at the end of searching process. To solve this problem, the inertia weight $W$ can be reduced linearly from maximum inertia weight $W_{\max }$ to minimum inertia weight $W_{\text {min }}$ during searching process shown as below due to the fact that a relative large inertia weight is beneficial for the global searching while a relative small inertia weight is beneficial for the local searching:

$$
W=W_{\max }-\text { iter } \cdot \frac{W_{\max }-W_{\min }}{\text { iter }_{\max }},
$$

where iter is the current generation number; iter $_{\max }$ is the total generation number.

3.4. Diagnostic Procedure. For the previous GPA method, due to the gas-path component performance parameters $\vec{p}$ as adaptive parameters, two steps should be included, in which the first step is to estimate engine degraded component performance parameters $\vec{p}$ as described in Section 2 with 


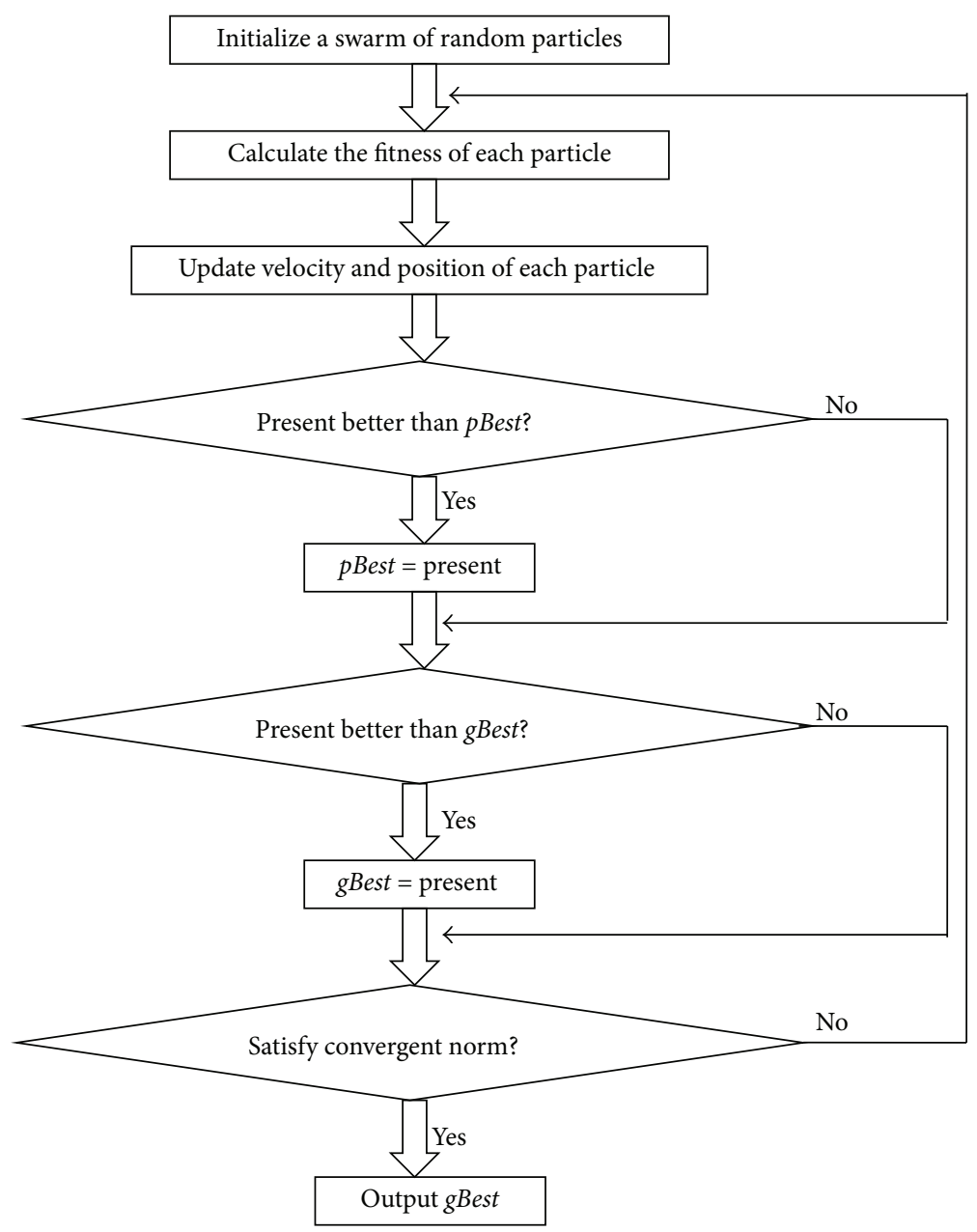

FIGURE 2: The flow chart of PSO searching process.

gas-path measurements and the second step is to estimate component health parameters $\Delta \overrightarrow{S F}$ by comparing healthy and degraded performance at component level. Here, PSOGPA has been developed to detect engine performance degradation by the usage of gas-path measurements $\vec{z}$, to directly output the component health parameters $\Delta \overrightarrow{S F}$ due to $\Delta \overrightarrow{S F}$ as adaptive parameters, and then (1) can be expressed by the following equation:

$$
\vec{z}=f(\vec{x}, \vec{u})+\vec{v}=f(\overrightarrow{\mathrm{map}}, \Delta \overrightarrow{S F}, \vec{u})+\vec{v},
$$

where $\overrightarrow{\mathrm{map}}$ is component characteristic maps for compressors, combustor, and turbines.

And the diagnostic procedure of the approach for the estimation of gas turbine health status is shown in Figure 3.

In the procedure of the approach for the estimation of gas turbine health status, an accurate nonlinear steadystate thermodynamic performance model as described in Section 3.2 has been established for the target gas turbine engine at the beginning of engine operation based on engine gas-path measurements. The performance of the gas turbine engine at such condition is regarded as healthy engine performance and the characteristic maps for gas-path components (e.g., compressors, combustor, and turbines) should accurately describe their performance behavior. In gas turbine engine operation, engine gas-path measurements are obtained continuously and used to estimate the component health parameters $\Delta \overrightarrow{S F}$ for assessment of engine overall health status due to engine degradation.

Here,

$$
\begin{aligned}
& \widehat{z}=\left[z_{1, \text { predicted }}, \ldots, z_{i, \text { predicted }}, \ldots, z_{M \text {,predicted }}\right], \\
& \vec{z}=\left[z_{1, \text { actual }}, \ldots, z_{i, \text { actual }}, \ldots, z_{M \text {,actual }}\right]
\end{aligned}
$$

where $\widehat{z}$ is the predicted gas-path measurement parameter vector obtained from the engine performance model; $\vec{z}$ is actual gas-path measurement parameters; $M$ is the total number of measured gas-path parameters:

$$
\begin{aligned}
& \Delta \overrightarrow{S F}=\left[\Delta S F_{\mathrm{C}, \mathrm{FC}}, \Delta S F_{\mathrm{C}, \mathrm{Eff}}, \Delta S F_{\mathrm{B}, \mathrm{Eff}}, \Delta S F_{\mathrm{C}, \mathrm{Eff}}, \Delta S F_{\mathrm{T}, \mathrm{FC}},\right. \\
& \left.\Delta S F_{\mathrm{T}, \mathrm{Eff}}\right],
\end{aligned}
$$

where $\Delta \overrightarrow{S F}$ is the gas-path component health parameters as a particle in the PSO. 


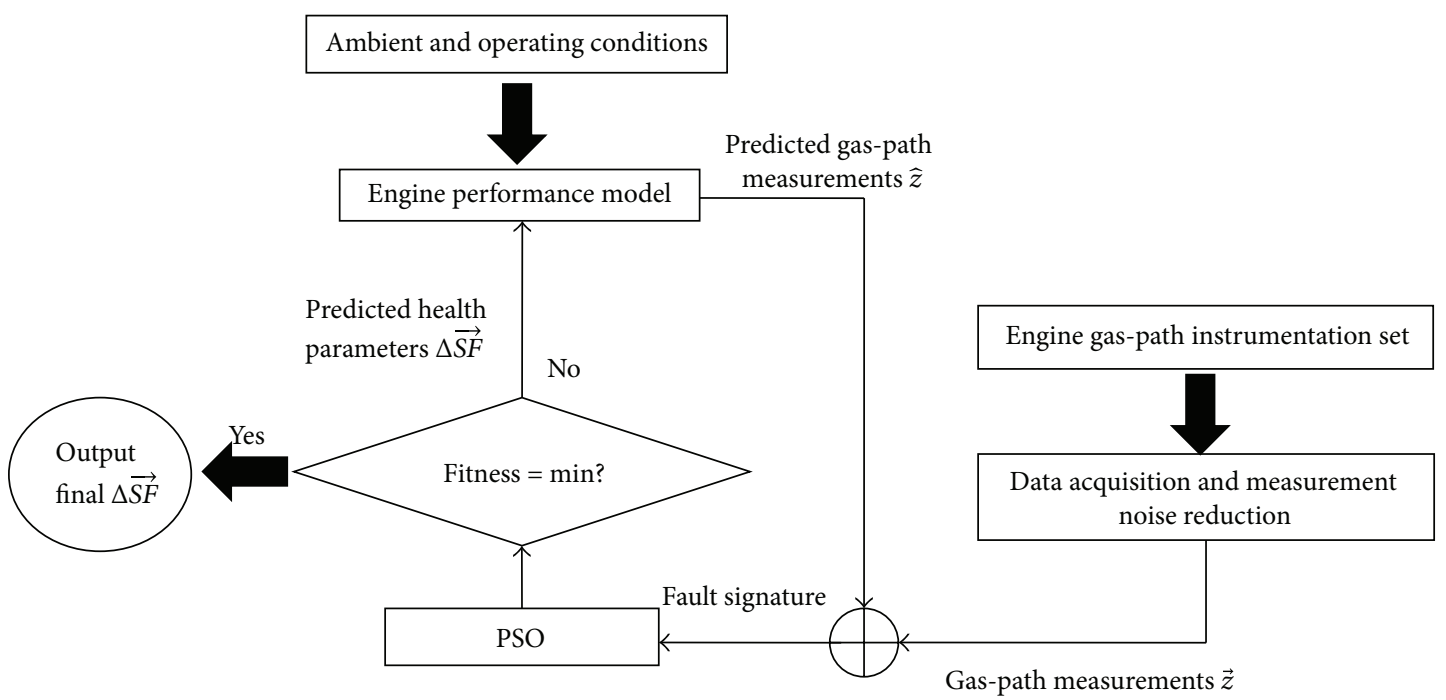

FIGURE 3: Diagnostic procedure of PSO-GPA.

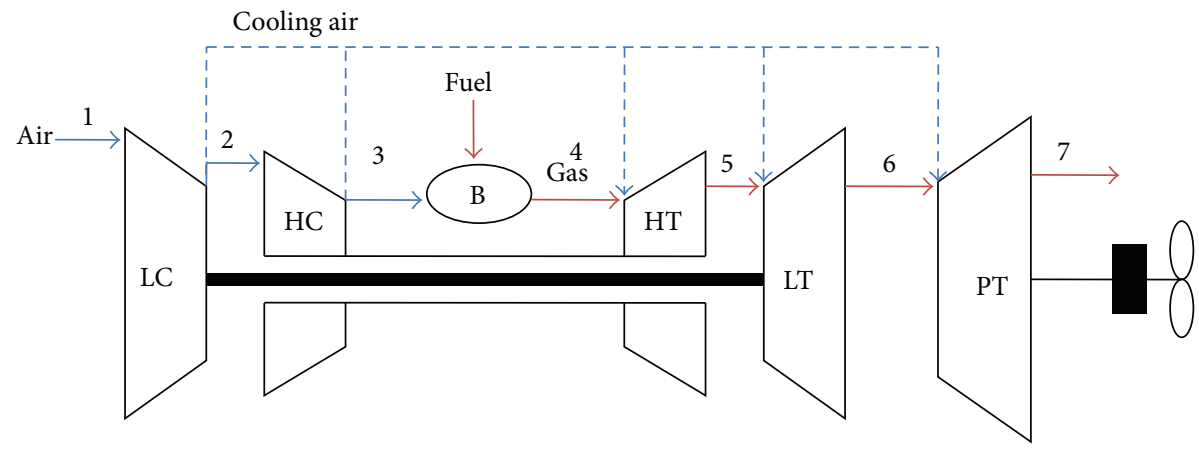

FIGURE 4: The schematic diagram of the three-shaft marine engine.

An optimization objective is defined in

$$
\text { Fitness }=\sqrt{\frac{\sum_{i=1}^{M}\left[\left(z_{i, \text { predicted }}-z_{i, \text { actual }}\right) / z_{i, \text { actual }}\right]^{2}}{M}},
$$

where Fitness is the optimization objective and when Fitness is gradually close to zero in search process, the predicted gaspath measurement parameters $\widehat{z}$ match with the actual gaspath measurement parameters $\vec{z}$, and then the final optimal gas-path component health parameters $\Delta \overrightarrow{S F}$ can be obtained.

\section{Application and Analysis}

The target engine chosen for demonstration of effectiveness of the proposed diagnostic approach is a model three-shaft marine gas turbine and its configuration is shown in Figure 4.

This three-shaft gas turbine includes a low-pressure compressor (LC), a high-pressure compressor (HC), a combustor (B), a high-pressure turbine (HT), a low-pressure turbine (LT), and a power turbine (PT), and the propeller is connected to the power turbine (PT) by a reduction gear box. The power output of LT is consumed by LC over a lowpressure shaft to condense air from intake duct and the power output of HT is consumed by HC over a high-pressure shaft to condense air from the outlet of LC. Then the high-pressure enters B with fuel supply and the combustion product enters HT, LT, and PT subsequently to drive turbines to produce power, and finally the power output of PT drives the ship by the propeller. In the meantime, due to the high temperature of gas entering turbine, turbine front vanes and blades should be cooled by cooling air extracted from compressors. When the engine runs at a certain operating condition, the fuel flow rate as the key control parameter is kept constant. And the basic performance specifications of the engine are as follows:

total air flow rate: $82.11 \mathrm{~kg} / \mathrm{s}$,

LC pressure ratio: 4.57 ,

HC pressure ratio: 4.53 ,

PT output power: $24265.1 \mathrm{~kW}$,

total thermal efficiency: $34.94 \%$.

The engine performance model for the target engine is created based on the simulation platform of MATLAB software. The input for engine performance model is ambient conditions (e.g., environmental temperature, pressure, and 
TABLE 1: Implanted degradation of major gas-path components.

\begin{tabular}{|c|c|c|c|c|c|c|c|c|c|c|c|c|}
\hline \multirow{2}{*}{ Component } & \multirow{2}{*}{ Mark number } & \multirow{2}{*}{ Symbols } & \multicolumn{7}{|c|}{ Implanted degradation (\%) } & \multirow{2}{*}{ Case 8} & \multirow{2}{*}{ Case 9} & \multirow{2}{*}{ Case 10} \\
\hline & & & Case 1 & Case 2 & Case 3 & Case 4 & Case 5 & Case 6 & Case 7 & & & \\
\hline \multirow{2}{*}{ LC } & 1 & $\Delta S F_{\mathrm{LC}, \mathrm{Eff}}$ & -2 & 0 & 0 & 0 & 0 & -2 & 0 & 0 & 0 & -2 \\
\hline & 2 & $\Delta S F_{\mathrm{LC}, \mathrm{FC}}$ & -2 & 0 & 0 & 0 & 0 & -2 & 0 & 0 & 0 & -2 \\
\hline \multirow{2}{*}{$\mathrm{HC}$} & 3 & $\Delta S F_{\mathrm{HC}, \mathrm{Eff}}$ & 0 & -2 & 0 & 0 & 0 & 0 & -2 & -2 & -2 & 0 \\
\hline & 4 & $\Delta S F_{\mathrm{HC}, \mathrm{FC}}$ & 0 & -2 & 0 & 0 & 0 & 0 & -2 & -2 & -2 & 0 \\
\hline $\mathrm{B}$ & 5 & $\Delta S F_{\mathrm{B}, \mathrm{Eff}}$ & 0 & 0 & -2 & 0 & 0 & 0 & 0 & 0 & -2 & -2 \\
\hline \multirow{2}{*}{ HT } & 6 & $\Delta S F_{\mathrm{HT}, \mathrm{Eff}}$ & 0 & 0 & 0 & -2 & 0 & -2 & 0 & -2 & -2 & 0 \\
\hline & 7 & $\Delta S F_{\mathrm{HT}, \mathrm{FC}}$ & 0 & 0 & 0 & 2 & 0 & 2 & 0 & 2 & 2 & 0 \\
\hline \multirow{2}{*}{ LT } & 8 & $\Delta S F_{\mathrm{LTTEff}}$ & 0 & 0 & 0 & 0 & 0 & 0 & -2 & 0 & 0 & 0 \\
\hline & 9 & $\Delta S F_{\mathrm{LT}, \mathrm{FC}}$ & 0 & 0 & 0 & 0 & 0 & 0 & 2 & 0 & 0 & 0 \\
\hline \multirow{2}{*}{ PT } & 10 & $\Delta S F_{\text {PT,Eff }}$ & 0 & 0 & 0 & 0 & -2 & 0 & 0 & -2 & 0 & -2 \\
\hline & 11 & $\Delta S F_{\mathrm{PT}, \mathrm{FC}}$ & 0 & 0 & 0 & 0 & 2 & 0 & 0 & 2 & 0 & 2 \\
\hline
\end{tabular}

relative humidity), fuel supply flow rate as operating condition, fuel composition, and fuel lower heating value, and the deviation of gas-path component health parameters $\Delta \overrightarrow{S F}$ (for the beginning of engine operation, $\Delta \overrightarrow{S F}=0$ ). The output of the performance model is engine output power, total thermal efficiency, and so forth, together with details of each component performance and of the thermodynamic parameters at various gas-path stations within the engine.

To test the effectiveness of the approach for health status estimation, it is assumed that the compressors, the combustor, and the turbines of the model engine may be degraded and single, dual, or triple components may be degraded in the meantime due to the fact that single component fault is most common in practical engine operation. The degradation of the engine is simulated by changing the deviation of gas-path component health parameters $\Delta \overrightarrow{S F}$ and ten engine degradation cases shown in Table 1 are used according to Diakunchak's experimental results [23].

Here case 1 to 5 has single component degradation only and case 6 to 10 has multiple components degraded meanwhile. The first five cases are used to test the ability of the approach of isolating a degraded component and further quantifying the degradation when only one component is degraded, while case 6 to 10 is used to test whether the approach can accurately estimate the engine degradation when multiple components are degraded simultaneously. Once the simulated gas-path measurements are collected, it is assumed that the implanted gas-path component degradation is unknown and the simulated gas-path measurements are used as the input to the developed diagnostic system described in Section 3.4.

The engine gas-path instrumentation set for the analysis of the model engine is shown in Table 2. It is assumed that all gas-path sensors are healthy, that is, no measurement bias. The deviation of the engine gas-path parameters may indicate degraded engine performance. The simulated samples of those parameters shown in Table 2 are collected and regarded as simulated gas-path measurements.
TABLE 2: Engine gas-path instrumentation set.

\begin{tabular}{lc}
\hline Symbols & Parameters \\
\hline$P_{0}$ & Ambient pressure \\
$T_{0}$ & Ambient temperature \\
$\phi$ & Relative humidity \\
$P_{1}$ & LC inlet pressure \\
$T_{1}$ & LC inlet temperature \\
$G_{f}$ & Fuel flow rate \\
$P_{2}$ & LC outlet pressure \\
$T_{2}$ & LC outlet temperature \\
$P_{3}$ & HC outlet pressure \\
$T_{3}$ & HC outlet temperature \\
$P_{5}(\mathrm{MPa})$ & HT outlet pressure \\
$T_{5}(\mathrm{~K})$ & HT outlet temperature \\
$P_{6}(\mathrm{MPa})$ & LT outlet pressure \\
$T_{6}(\mathrm{~K})$ & LT outlet temperature \\
$T_{7}(\mathrm{~K})$ & PT outlet temperature \\
$n_{1}(\mathrm{r} / \mathrm{min})$ & LT shaft rotational speed \\
$n_{2}(\mathrm{r} / \mathrm{min})$ & HT shaft rotational speed \\
\hline
\end{tabular}

By implanting the various component degradations shown in Table 1 into the engine performance model, respectively, the deviations of gas-path measurements (fault signatures) relative to the measurements when the engine is healthy in the ten Test Cases are shown in Table 3.

It shows that different engine degradations induce various engine performance deviations shown by different gas-path measurement deviations. To test the effectiveness of the approach, these sets of the gas-path measurements are input into the developed diagnostic system, respectively, assuming that the degradation of the compressors, the turbines, and the combustor is unknown.

In this study, the simulated engine performance with implanted different engine component degradations is called "actual performance" and the predicted engine performance 
Table 3: Measurement deviations (i.e., fault signatures) in ten Test Cases ( $T_{0}=288.15 \mathrm{~K}, P_{0}=101325 \mathrm{~Pa}$, and $\left.G_{f}=1.82 \mathrm{~kg} / \mathrm{s}\right)$.

\begin{tabular}{lcccccccccc}
\hline \multirow{2}{*}{ Symbols } & \multicolumn{8}{c}{ Measurement deviations (\%) } & (relative to the measurements when the engine is healthy) \\
& Test Case 1 & Test Case 2 & Test Case 3 & Test Case 4 & Test Case 5 & Test Case 6 & Test Case 7 & Test Case 8 & Test Case 9 & Test Case 10 \\
\hline$P_{2}$ & 1.634 & -0.839 & 1.047 & -1.468 & -2.660 & 0.188 & 5.528 & -5.075 & -1.223 & 0.053 \\
$T_{2}$ & -0.254 & -0.256 & 0.322 & -0.448 & -0.807 & -0.709 & 1.730 & -1.527 & -0.373 & -0.751 \\
$P_{3}$ & 0.935 & 0.946 & 1.437 & 3.792 & -1.254 & 4.700 & 2.0579 & 3.443 & 6.048 & 1.132 \\
$T_{3}$ & -0.444 & -0.449 & 0.417 & 1.113 & -0.360 & 0.670 & -0.141 & 0.318 & 1.098 & -0.392 \\
$P_{5}$ & 0.913 & 0.923 & 1.421 & 1.490 & -1.023 & 2.398 & 3.816 & 1.338 & 3.763 & 1.312 \\
$T_{5}$ & -0.832 & -0.841 & 0.640 & -1.492 & 0.592 & -2.349 & -0.916 & -1.680 & -1.666 & 0.407 \\
$P_{6}$ & 0.801 & 0.810 & 1.265 & 1.320 & 0.846 & 2.118 & 1.578 & 2.896 & 3.340 & 2.886 \\
$T_{6}$ & -0.8749 & -0.885 & 0.604 & -1.499 & 1.001 & -2.400 & -1.767 & -1.307 & -1.753 & 0.741 \\
$T_{7}$ & -1.111 & -1.124 & 0.325 & -1.867 & 0.205 & -3.021 & -2.234 & -2.713 & -2.657 & -0.571 \\
$n_{1}$ & -0.315 & 0.863 & 0.802 & 1.386 & -0.950 & 1.068 & 2.016 & 1.035 & 2.877 & -0.586 \\
$n_{2}$ & -0.530 & 0.255 & 0.410 & 2.709 & 0.306 & 2.285 & -2.703 & 2.907 & 3.156 & 0.192 \\
\hline
\end{tabular}

TABLE 4: Maximum measurement noise.

\begin{tabular}{lcc}
\hline Measurement & Range & Typical error \\
\hline & $3 \sim 45$ psia & $\pm 0.5 \%$ \\
& $8 \sim 460$ psia & $\begin{array}{c} \pm .5 \% \text { or } 0.125 \text { psia } \\
\text { whichever is greater }\end{array}$ \\
\hline & $-65 \sim 290^{\circ} \mathrm{C}$ & $\pm 3.3^{\circ} \mathrm{C}$ \\
& $290 \sim 1000^{\circ} \mathrm{C}$ & $\pm \sqrt{2.5^{2}+(0.0075 \cdot t)^{2}}$ \\
& $1000 \sim 1300^{\circ} \mathrm{C}$ & $\pm \sqrt{3.5^{2}+(0.0075 \cdot t)^{2}}$ \\
\hline
\end{tabular}

by using the developed diagnostic system based on gas-path measurements is called "predicted performance."

Due to the fact that measurement noise is inevitable in practical gas-path measurements and can cause a negative effect on health status estimation results, measurement noise is introduced in the simulated gas-path measurements to make the analysis more realistic. The maximum measurement noise for various gas-path measurement parameters is based on the information provided by Dyson and Doel [24], as shown in Table 4.

To reduce the negative effect of measurement noise on diagnostic analysis, multiple gas-path measurement samples are obtained in the simulation and a 10-point rolling average [3] can be applied to get an averaged measurement sample before the measurements are input into the developed diagnostic system. The mathematical expression for the rolling averaging is shown in

$$
\overline{z_{i}}=\frac{1}{P} \sum_{i=1}^{P} z_{i}
$$

where $z_{i}$ is gas-path measurement samples and $P$ is the number of samples ( $P=10$ for ten-point rolling average).

The PSO parameters chosen for this paper are shown in Table 5, where 80 PSO generations with population size of 60 were used to search for the optimal component health parameters $\Delta \overrightarrow{S F}$.
TABLE 5: PSO parameters.

\begin{tabular}{lc}
\hline Parameters & Value \\
\hline Population size & 60 \\
Number of generations & 80 \\
\hline
\end{tabular}

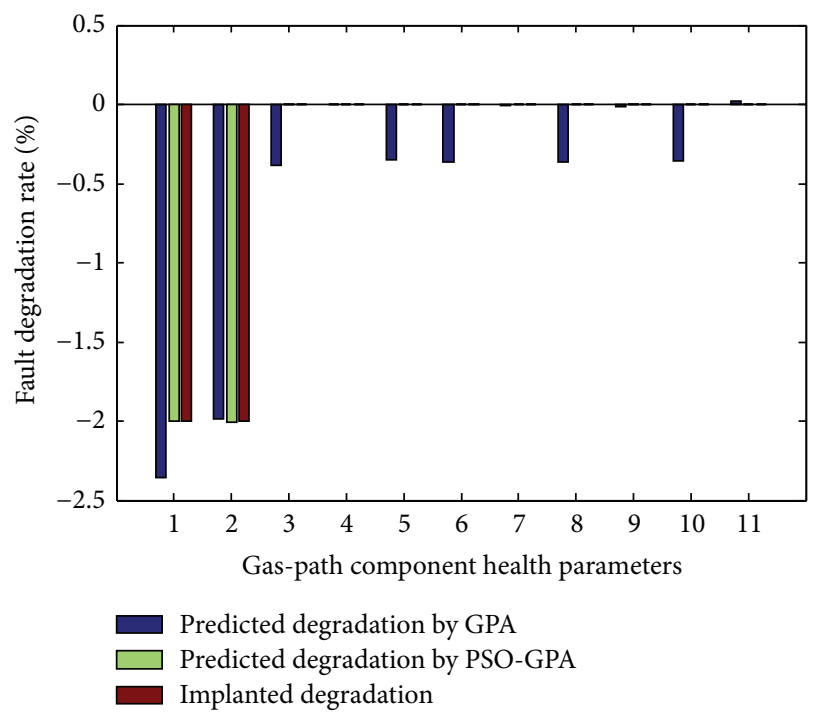

Figure 5: Diagnostic results for Test Case 1.

4.1. Test Case 1 to 5. From Figures 5-9, it can be seen that due to the large number of components within engine and the existence of gas-path measurement noise the smearing effect can be found and some misleading degradation predictions for healthy components have been made by the typical GPA due to the fact that the nature of its algorithm is local optimum searching method. However, the degraded component is successfully isolated and the magnitude of the fault degradation rate is obtained by PSO-GPA due to the fact that the nature of its algorithm is global optimum searching 


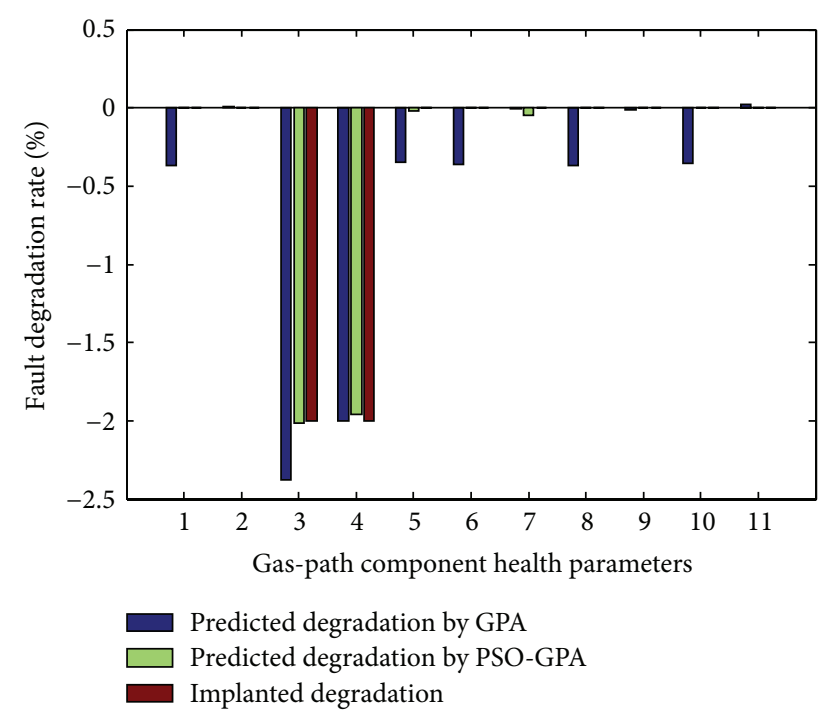

Figure 6: Diagnostic results for Test Case 2.

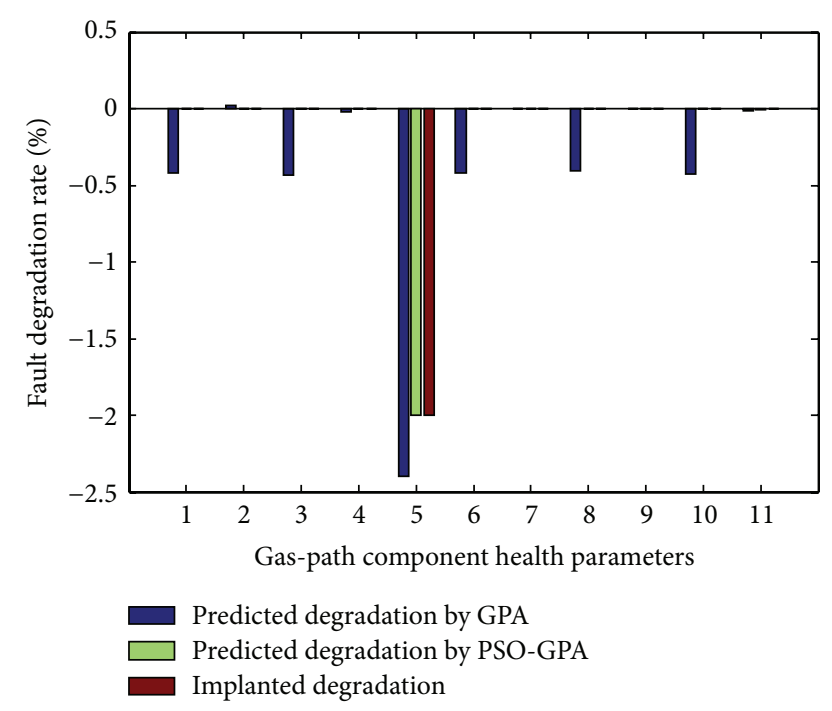

FIgure 7: Diagnostic results for Test Case 3.

method. Moreover, the degradation rate predicted by PSOGPA is more accurate than that by GPA.

4.2. Test Case 6 to 10. Due to the fact that there are many combination types of dual and triple component fault pattern, here only two Test Cases among dual component fault pattern and three Test Cases among triple component fault pattern are used to test the effectiveness of the PSO-GPA method. From Figures 10-14, it is shown that the degraded dual and triple components are successfully recognized and isolated by PSO-GPA method, while the smearing effect can be found and some misleading degradation predictions for healthy components have been made by the typical GPA. The predicted degradation by PSO-GPA is almost the same as implanted degradation. And the related PSO searching

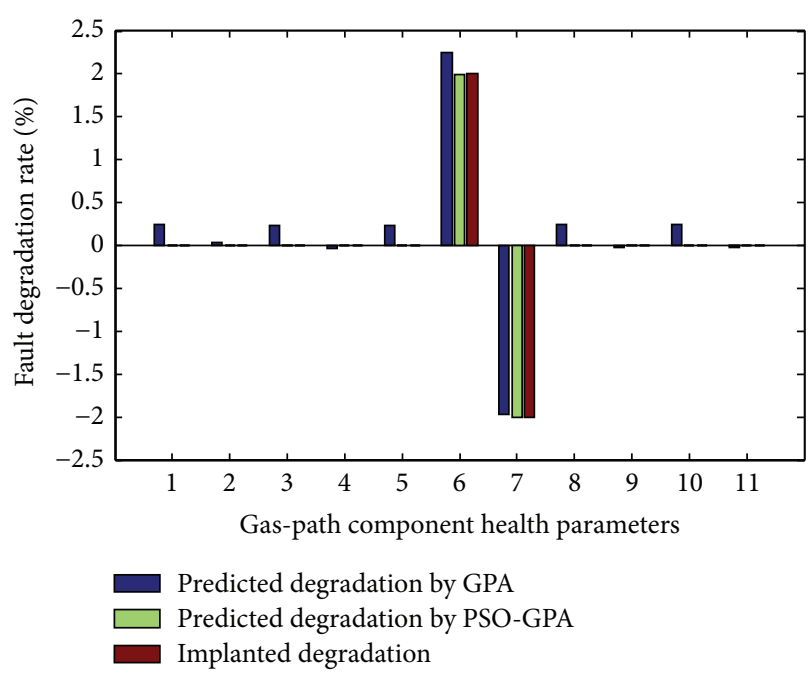

Figure 8: Diagnostic results for Test Case 4.

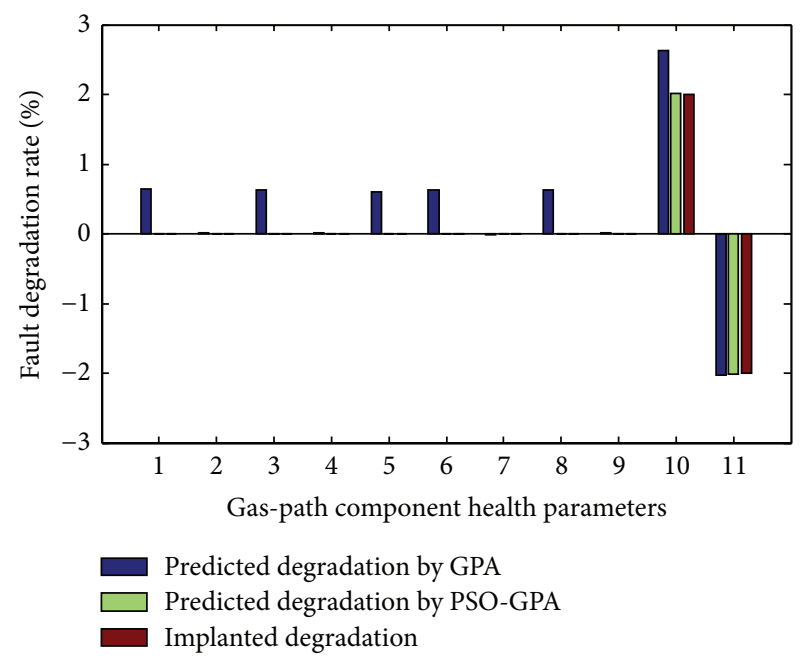

Figure 9: Diagnostic results for Test Case 5.

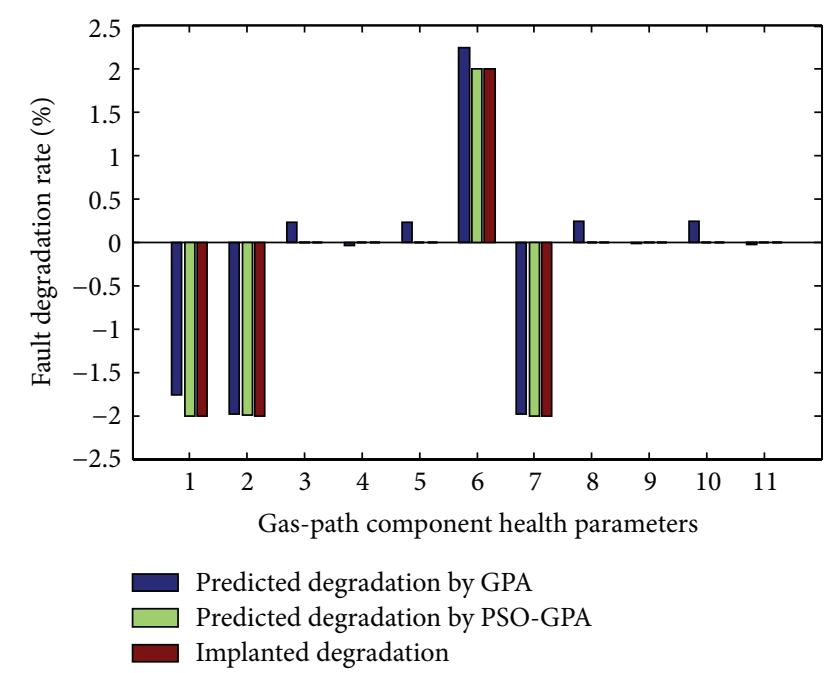

Figure 10: Diagnostic results for Test Case 6. 


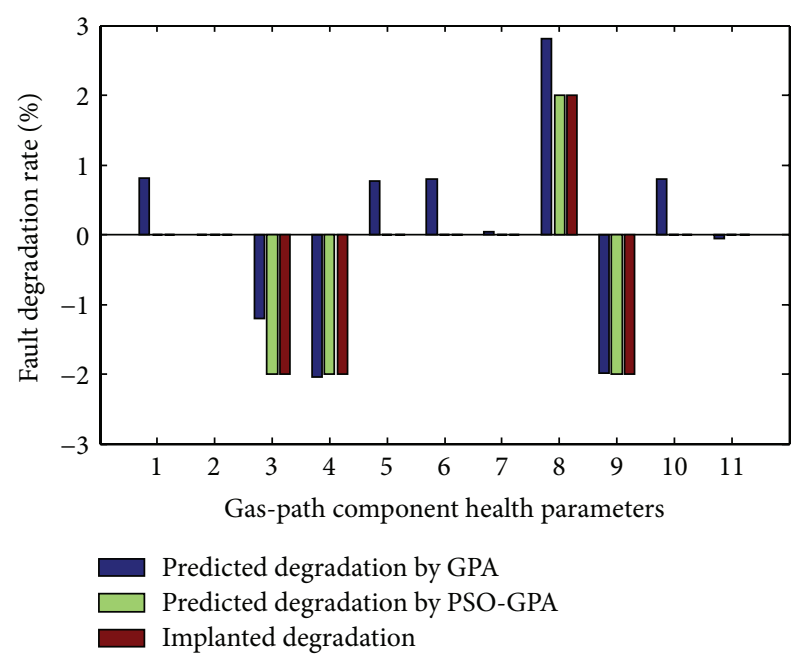

FIgURe 11: Diagnostic results for Test Case 7.

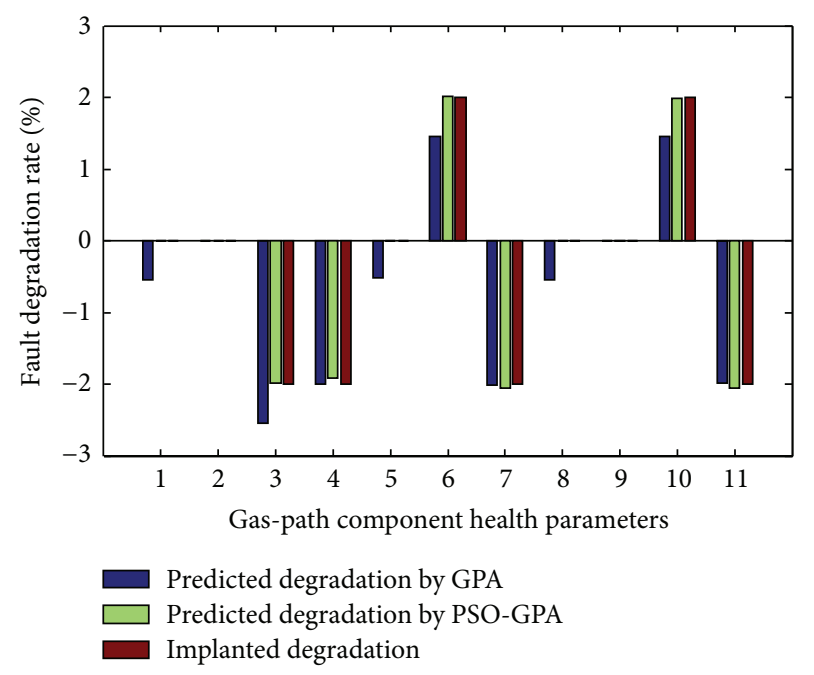

FIgURE 12: Diagnostic results for Test Case 8.

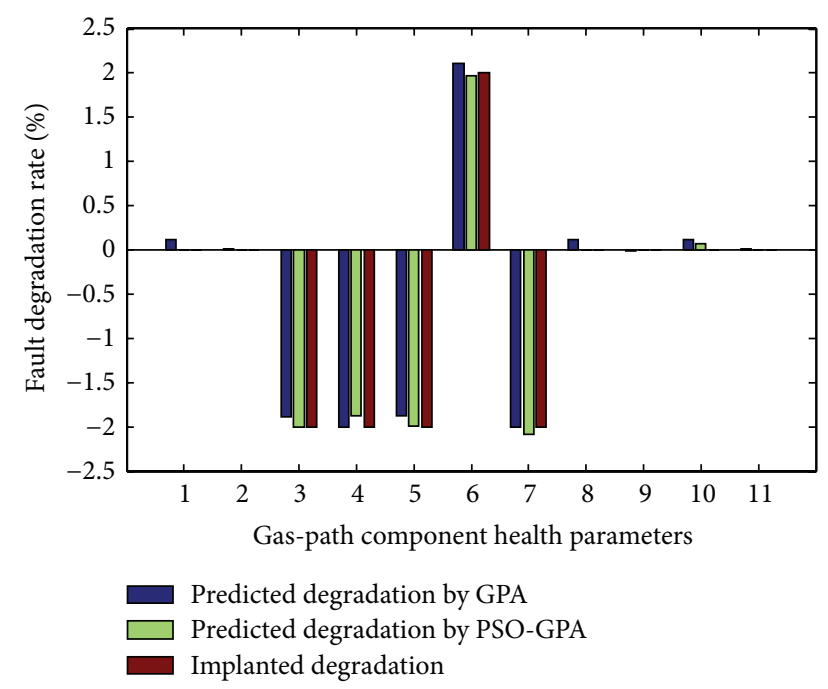

FIgure 13: Diagnostic results for Test Case 9.

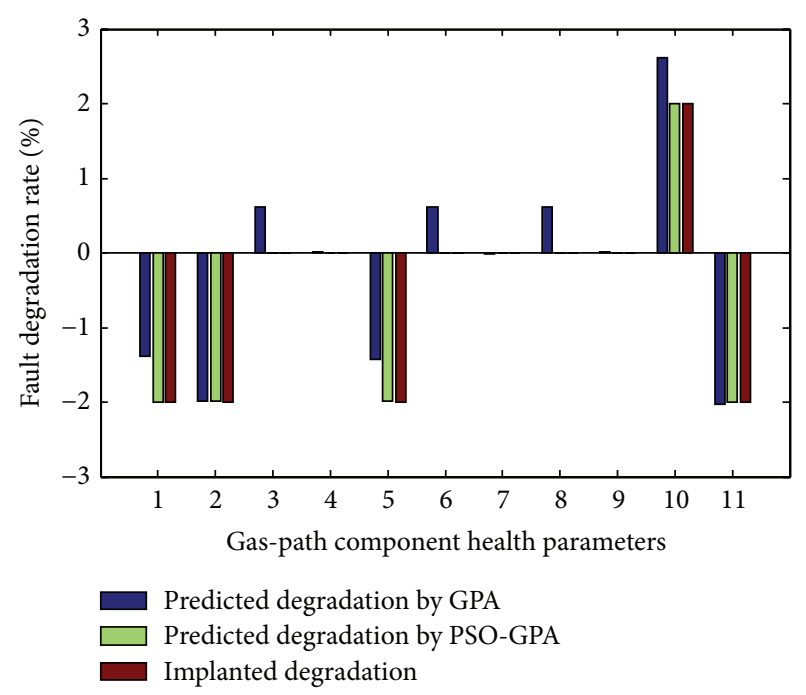

FIgURE 14: Diagnostic results for Test Case 10.

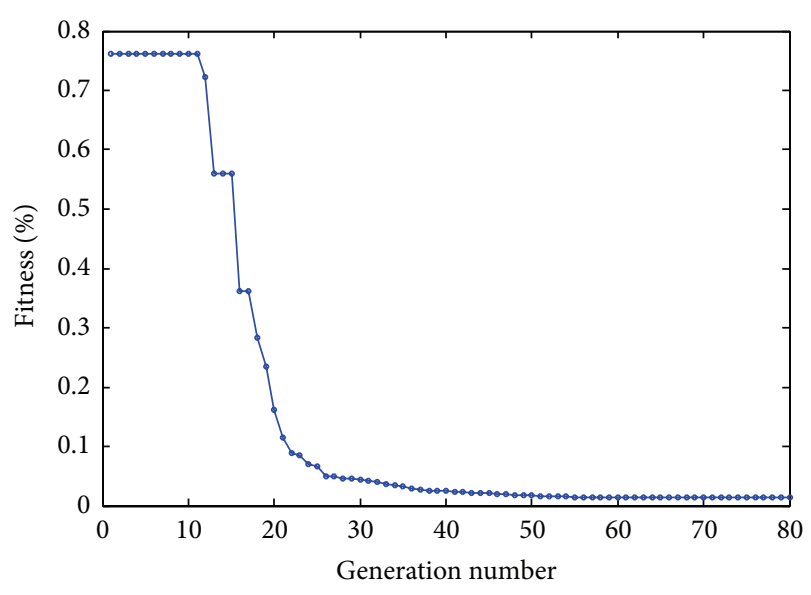

FIGURE 15: PSO fitness versus PSO generations.

process for Test Case 10 is shown in Figure 15 for a total number of 80 PSO generations.

\section{Conclusion and Discussion}

In this study, a PSO-GPA method has been developed to effectively isolate degraded components and accurately quantify the magnitude of the detected faults by the usage of gas-path measurements. The effectiveness of the proposed approach has been verified by case studies compared with the typical GPA method for a model three-shaft marine gas turbine where the number of components within engine is large which enlarges the dimension of fault coefficient matrix. Some conclusions have been obtained as follows.

(1) The smearing effect which is commonly observed by typical GPA method can be effectively eliminated by the proposed approach, and the degraded components are successfully isolated due to the fact that 
the nature of the typical GPA method is a local optimum searching method while PSO-GPA is a global optimum searching method.

(2) The proposed approach can be used for diagnosis for single and multiple fault patterns of major gas-path components, and the fault degradation rate predicted is almost the same as that of implanted fault patterns.

(3) Although the verification of the effectiveness is based on the case studies with pseudo "actual" gas-path measurements which are simulated by engine performance model implanted with various fault patterns and are added on random measurement noise, it shows a great potential for application for complex gas turbine engine in which the number of gas-path components is large.

(4) The time cost by the approach for one Test Case is within 40 seconds involving generation number of 80 and population size of 60 by using a laptop computer with a $2.0 \mathrm{GHz}$ dual processor, which is longer than the typical GPA methods with only few seconds. Thus the proposed approach is suitable for the application of off-line health monitoring.

\section{Nomenclature}

$\begin{array}{ll}\text { GPA: } & \text { Gas-path analysis } \\ \Delta \overrightarrow{S F}: & \text { Component health parameter vector } \\ \vec{z}: & \text { Gas-path measurement parameter vector } \\ \vec{p}: & \text { Component performance parameter vector } \\ \vec{u}: & \text { Ambient and operating condition vector } \\ \vec{v}: & \text { Transducer measurement noise vector } \\ \Delta S F_{\mathrm{C}, \mathrm{FC}}: & \text { Compressor flow capacity index } \\ \Delta S F_{\mathrm{C}, \mathrm{Eff}}: & \text { Compressor isentropic efficiency index } \\ \Delta S F_{\mathrm{B}, \mathrm{Eff}}: & \text { Combustion efficiency index } \\ \Delta S F_{\mathrm{T}, \mathrm{FC}}: & \text { Turbine flow capacity index } \\ \Delta S F_{\mathrm{T}, \mathrm{Eff}}: & \text { Turbine isentropic efficiency index } \\ \mathrm{LC}: & \text { Low-pressure compressor } \\ \mathrm{HC}: & \text { High-pressure compressor } \\ \mathrm{B}: & \text { Combustor } \\ \mathrm{HT}: & \text { High-pressure turbine } \\ \mathrm{LT}: & \text { Low-pressure turbine } \\ \mathrm{PT}: & \text { Power turbine. }\end{array}$

\section{Subscripts}

C: Compressor

FC: Flow capacity

deg: Degraded condition

B: Combustor

Eff: Isentropic efficiency

T: Turbine

$\mathrm{H}$ : High-pressure

L: Low-pressure

LC: Low-pressure compressor

HC: High-pressure compressor

HT: High-pressure turbine
LT: Lower-pressure turbine

PT: Power turbine

$f$ : Fuel flow.

\section{Conflict of Interests}

The authors declare that there is no conflict of interests regarding the publication of this paper.

\section{Acknowledgment}

This research is supported by the Fundamental Research Funds for the Central Universities (HEUCFZ1005).

\section{References}

[1] Y. Liu and M. Su, "Nonlinear model based diagnostic of gas turbine faults: a case study," in Proceedings of the ASME Turbo Expo: Turbine Technical Conference and Exposition, pp. 1-8, American Society of Mechanical Engineers, 2011.

[2] L. A. Urban, "Gas path analysis applied to turbine engine condition monitoring," Journal of Aircraft, vol. 10, no. 7, pp. 400403, 1973.

[3] Y. G. Li and R. Singh, "An advanced gas turbine gas path diagnostic system-PYTHIA," in Proceedings of the 47th International Symposium on Air Breathing Engines, Paper No. ISABE2005-1284, Munich, Germany, 2005.

[4] Y. G. Li, P. Pilidis, and M. A. Newby, "An adaptation approach for gas turbine design-point performance simulation," Journal of Engineering for Gas Turbines and Power, vol. 128, no. 4, pp. 789-795, 2006.

[5] Y. G. Li, "Gas turbine performance and health status estimation using adaptive gas path analysis," Journal of Engineering for Gas Turbines and Power, vol. 132, no. 4, Article ID 041701, 2010.

[6] A. Gulati, M. Zedda, and R. Singh, "Gas turbine engine and sensor multiple operating point analysis using optimization techniques," in Proceedings of the 36th AIAA/ASME/SAE/ASEE Joint Propulsion Conference and Exhibit, AIAA-2000-3716, 2000.

[7] M. Zedda and R. Singh, "Gas turbine engine and sensor fault diagnosis using optimization techniques," AIAA Journal of Propulsion \& Power, vol. 18, no. 5, pp. 1019-1025, 2002.

[8] M. Wallin and T. Grönstedt, "A comparative study of genetic algorithms and gradient methods for RM12 turbofan engine diagnostics and performance estimation," in Proceedings of the ASME Turbo Expo 2004: Power for Land, Sea, and Air, GT200453591, Vienna, Austria, June 2004.

[9] Y. G. Li, "A genetic algorithm approach to estimate performance status of gas turbines," in Proceedings of the ASME Turbo Expo 2008: Power for Land, Sea, and Air, Paper no. GT2008-50175, pp. 431-440, International Gas Turbine Institute, Berlin, Germany, June 2008.

[10] I. Loboda, Y. Feldshteyn, and V. Ponomaryov, "Neural networks for gas turbine fault identification: multilayer perceptron or radial basis network?" in Proceedings of the ASME Turbo Expo: Turbine Technical Conference and Exposition, pp. 465-475, ASME, Vancouver, Canada, June 2011.

[11] M. F. A. Ghafir, Y. G. Li, and L. Wang, "Creep life prediction for aero gas turbine hot section component using artificial neural networks," Journal of Engineering for Gas Turbines and Power, vol. 136, no. 3, Article ID 031504, 2014. 
[12] F. Sahin, M. C. Yavuz, Z. Arnavut, and Ö. Uluyol, "Fault diagnosis for airplane engines using Bayesian networks and distributed particle swarm optimization," Parallel Computing, vol. 33, no. 2, pp. 124-143, 2007.

[13] L. Wang, Y. G. Li, and M. F. A. Ghafir, "Rough set diagnostic frameworks for gas turbine fault classification," in Proceedings of the ASME Turbo Expo 2013: Turbine Technical Conference and Exposition, p. V002T07A007, American Society of Mechanical Engineers, June 2013.

[14] X. Pu, S. Liu, H. Jiang, and D. Yu, "Sparse bayesian learning for gas path diagnostics," Journal of Engineering for Gas Turbines and Power, vol. 135, no. 7, Article ID 071601, 2013.

[15] A. Salar, A. K. Sedigh, S. Hosseini, and H. Khaledi, "A hybrid EKF-fuzzy approach to fault detection and isolation of industrial gas turbines," in Proceedings of the ASME Turbo Expo: Turbine Technical Conference and Exposition, pp. 251-260, 2011.

[16] M. Mucino, CCGT performance simulation and diagnostics for operations optimisation and risk management [M.S. thesis], Cranfield University, Cranfield, UK, 2007.

[17] Y.-L. Ying, Y.-P. Cao, S.-Y. Li, and Z.-T. Wang, "Study on flow parameters optimisation for marine gas turbine intercooler system based on simulation experiment," International Journal of Computer Applications in Technology, vol. 47, no. 1, pp. 56-67, 2013.

[18] Y.-L. Ying, Y.-P. Cao, and S.-Y. Li, "Research on fuel supply rate of marine intercooledcycle engine based on simulation experiment," International Journal of Computer Applications in Technology, vol. 48, no. 3, pp. 212-221, 2013.

[19] E. Larsson, J. Åslund, E. Frisk, and L. Eriksson, "Gas turbine modeling for diagnosis and control," Journal of Engineering for Gas Turbines and Power, vol. 136, no. 7, Article ID 071601, 2014.

[20] R. C. Eberhart and J. Kennedy, "A new optimizer using particle swarm theory," in Proceedings of the 6th International Symposium on Micro Machine and Human Science, pp. 39-43, October 1995.

[21] R. C. Eberhart and Y. Shi, "Tracking and optimizing dynamic systems with particle swarms," in Proceedings of the Congress on Evolutionary Computation, vol. 1, pp. 94-100, May 2001.

[22] A. P. Engelbrecht, "Particle swarm optimization," in Proceedings of the Companion Publication of the 2014 Genetic and Evolutionary Computation Conference (GECCO '14), pp. 381-406, July 2014.

[23] I. S. Diakunchak, "Performance deterioration in industrial gas turbines , Trans," Journal of Engineering for Gas Turbines and Power, vol. 114, no. 2, pp. 161-168, 1992.

[24] R. J. E. Dyson and D. L. Doel, "CF-80 Condition monitoringthe engine manufacturing's involvement in data acquisition and analysis," AIAA-84-1412, 1987. 


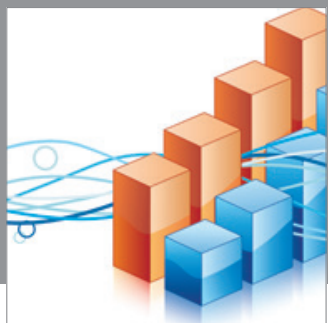

Advances in

Operations Research

mansans

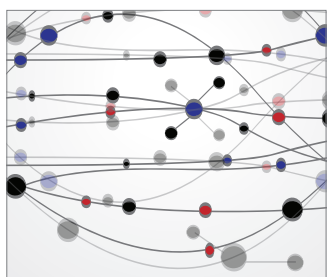

The Scientific World Journal
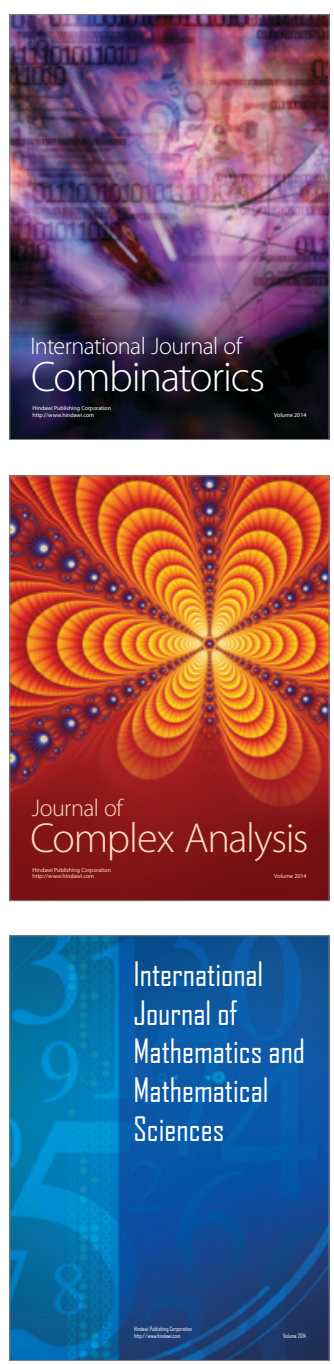
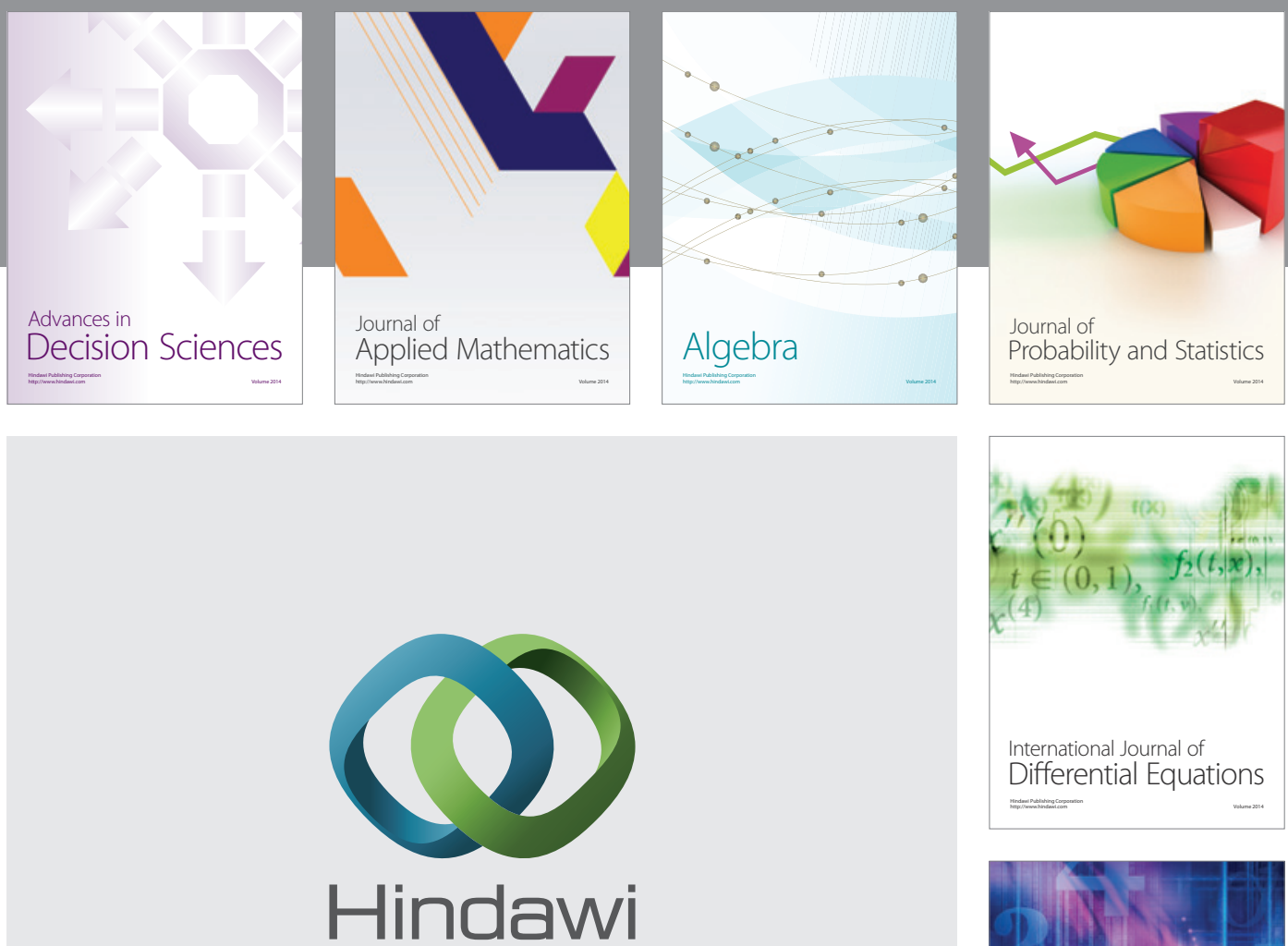

Submit your manuscripts at http://www.hindawi.com
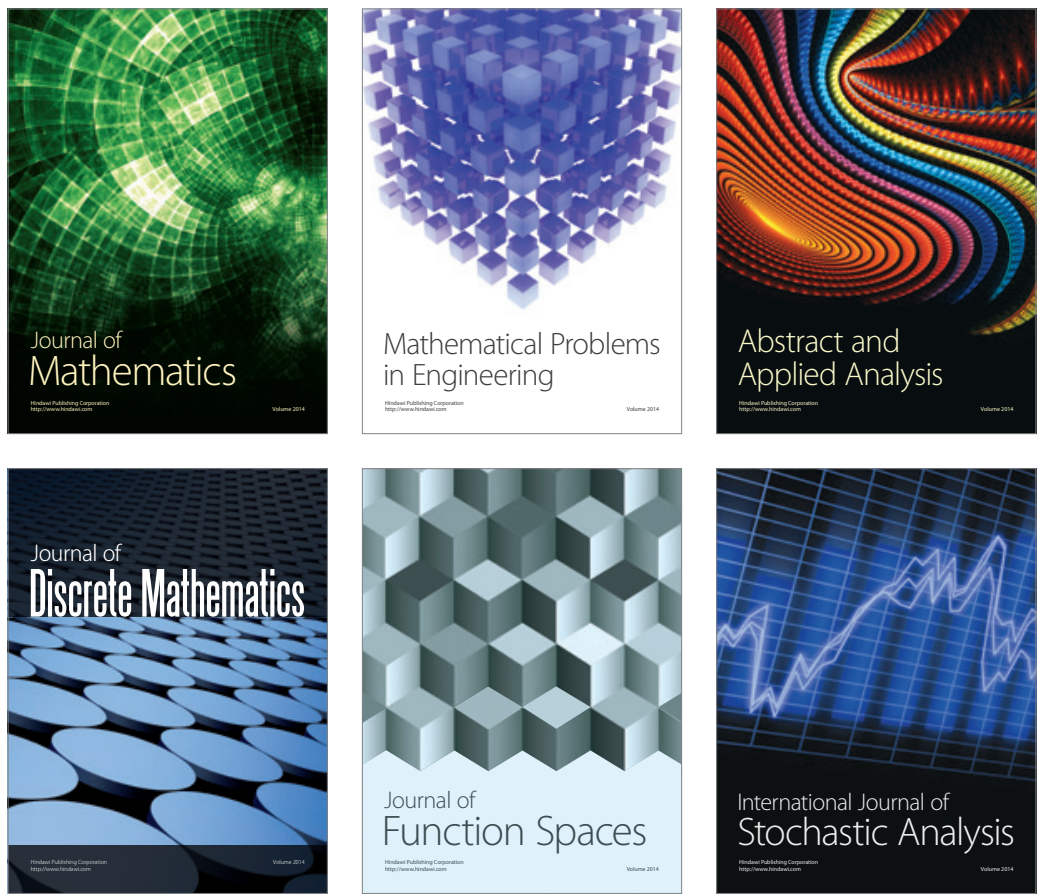

Journal of

Function Spaces

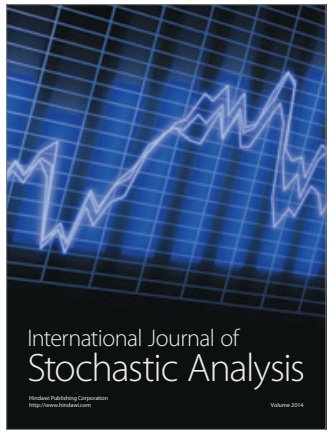

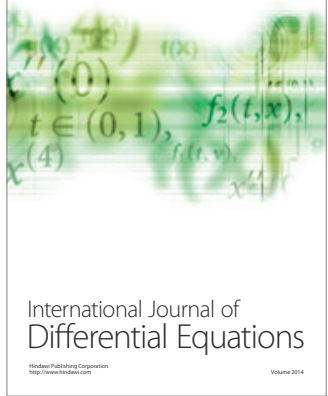
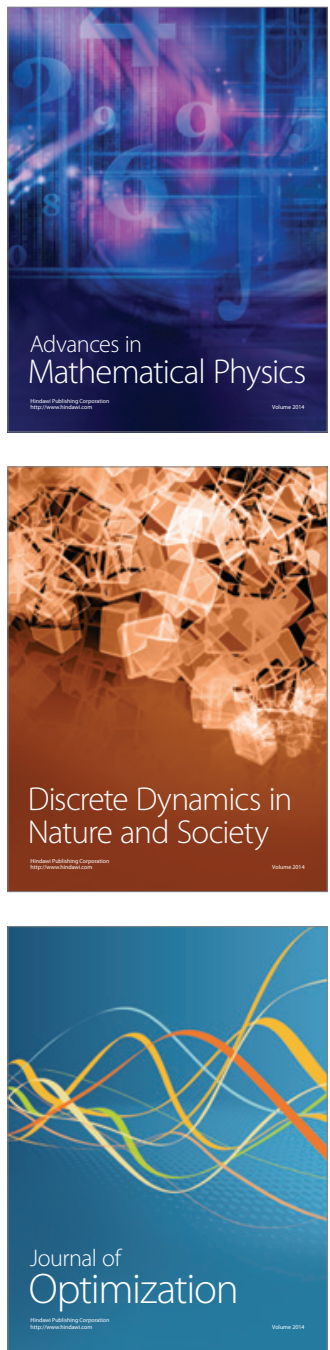